\section{Study time, recall time, meaningfulness, and recognition latency in paired-associate learning*}

\author{
RONALD LEY†, State University of New York at Albany, Albany, N.Y. 12203 \\ and \\ DAVID LOCASCIO. Fairleigh Dickinson University, Madison, N.J. 07470
}

Four groups of 24 undergraduates each learned one of two lists of eight paired associates in which half of the response terms were composed of low-meaningfulness (M) CVCs and the other half high-M CVCs. Within the two levels of equated M. two response terms of each level had short recognition latencies (RL), the other two, long RIs. Each group learned one list under one of four combinations of study time and recall time, viz, 1 -sec study and $1-\mathrm{sec}$ recall, 1 -sec study and $3^{1 / 2}$-sec recall, $3^{1 / 2}$-sec study and 1 -sec recall, or $3^{1 / 2}-$ sec study and $3 \frac{1}{2}$-sec recall. The difference between the learning rates of high-and low-M pairs was greater under the 1 -sec recall condition than under the $31 / 2-\mathrm{sec}$ condition, results accounted for on the basis of Martin's perceptual encoding hypothesis. Although high-M pairs were learned in fewer trials than low-M pairs, no differences were found between the number of trials to learn the short- and long-RL pairs.

In a series of paired-associate learning (PAL) experiments (Ley, 1968; Ley \& Anderson, 1969; Ley \& Locascio, 1970a), a consistent interaction between meaningfulness (Mi) and presentation rate was found in which the differences between the learning rates of low- and high-M response terms decreased as presentation rate increased. Postman (personal communication) pointed out that the procedure of varying study interval and recall interval simultaneously is essentially nonanalytical, since there is no way to determine which component of presentation rate (study time or recall time) is responsible for the effect of presentation rate on performance.

The primary purpose of the present study was to analyze presentation rate in terms of the relative effects of study time and recall time by means of an orthogonal arrangement of presentation rate, i.e., two different study times ( 1 -sec and $31 / 2-\mathrm{sec})$ were each matched with one of two different recall times ( 1 -sec or $3 \frac{1}{2} 2$-sec), thus providing means for determining whether study time and/or recall time account for the interaction between $M$ and presentation rate.

The secondary purpose of the present study was to examine the effects of recognition latency (RL = the time elapsing between the presentation of a verbal unit and the onset of the pronunciation of the unit)

× This research was supported in part by a State University of New York Research Foundation grant-in-aid to the first author.

$\rightarrow$ Requests for reprints should be sent to Ronald Ley. State University of New York at Albany. Albany. N.Y. 12203. of response terms in PAL, within levels of high and low M. Although RL has been shown to be significantly correlated $(\mathrm{r}=.36)$ with $\mathrm{PAL}$ rate (Johnson, 1964), it is conceivable that RL does not have an effect on performance independent of its relationship with $M$. If $R L$ does have an effect on PAL rate, independent of $M$, it would be expected that in a PAL task, in which response terms (CVC rate will be a function of $R L$, i.e., trigrams with short RLs will be learned in fewer trials than trigrams with long RLs.

\section{SUBJECTS}

The Ss were 96 undergraduate paid volunteers ( 48 females and 48 males) from the State University of New York at Albany, naive with respect to prior experience in verbal learning studies. trigrams) are equated on $\mathrm{M}$, learning
MATERIALS

In the PAL lists, the stimulus terms were eight two-digit numbers, selected using the procedures and restrictions employed by Ley \& Locascio (1970a). The response terms were 16 consonant-vowel-consonant (CVC) verbal units which had been assessed for associative latency ( $R L$ in the present study) by Johnson (1964) and for $\mathrm{M}$ ( $\mathrm{m}$-scaled meaningfulness) by Noble (1961). Using $M$ as the primary selection criterion, 8 low- and 8 high-M CVC units were selected. Within each of these two M levels, 4 of the CVC units selected had short-RL values and 4 had long-RL values. The $M$ and RL values for each of the 16 selected CVCs are given in Table 1 .

From the 16 selected CVCs, two PA lists were constructed. Each list contained four high- and four low-M response term groups, and within each group were two short and two long-RL terms. For both lists, four tapes for use on a memory drum were constructed; all contained the same stimulus and response terms but were paired in different combinations, following the procedure employed by Ley \& Locascio (1970a).

A practice list containing eight different PAs was constructed and typed on a separate practice tape. The practice list was similar to the test lists, except that the stimulus terms were different two-digit numbers and the response terms were eight different CVCs selected randomly from the remainder of Johnson's (1964) list. Care was taken to avoid using stimulus or response terms on the practice list that had formal similarity to the stimulus and response terms on the test lists.

\section{PROCEDURE}

The experimental procedure in the present study was the same for all Ss, except that an equal number (24 females and 24 males) were assigned

Table 1

Meaningfulness (M) and Recognition Latency (RL) Values for the 16 CVC Response Terms of the Two PAL Lists

\begin{tabular}{|c|c|c|c|c|c|c|}
\hline \multirow[b]{2}{*}{ RL } & \multicolumn{3}{|c|}{ List 1} & \multicolumn{3}{|c|}{ List 2} \\
\hline & $\mathrm{CVC}$ & $\mathbf{M}$ & $\mathrm{RL}$ & $\mathrm{CVC}$ & 31 & $\mathrm{RL}$ \\
\hline $\begin{array}{l}\text { Long Latency } \\
\text { Nean }\end{array}$ & $\begin{array}{l}\text { NIJ } \\
\text { VAW }\end{array}$ & $\begin{array}{l}1.00 \\
1.17 \\
1.08\end{array}$ & $\begin{array}{l}\text { Low } \\
2.81 \\
2.82 \\
2.82\end{array}$ & $\begin{array}{r}\text { Meaningfulness } \\
\text { DEJ } \\
\text { VIJ }\end{array}$ & $\begin{array}{l}1.46 \\
1.23 \\
1.34\end{array}$ & $\begin{array}{l}2.96 \\
3.25 \\
3.10\end{array}$ \\
\hline $\begin{array}{l}\text { Short Latency } \\
\text { Mean }\end{array}$ & $\begin{array}{l}\text { QUC } \\
\text { XIP }\end{array}$ & $\begin{array}{l}1.02 \\
1.14 \\
1.08\end{array}$ & $\begin{array}{l}1.65 \\
1.97 \\
1.81\end{array}$ & $\begin{array}{l}\text { TUQ } \\
\text { GAH }\end{array}$ & $\begin{array}{l}1.53 \\
1.17 \\
1.35\end{array}$ & $\begin{array}{l}1.54 \\
1.73 \\
1.64\end{array}$ \\
\hline $\begin{array}{l}\text { Long Latency } \\
\text { Mean }\end{array}$ & $\begin{array}{l}\text { GAN } \\
\text { LEW }\end{array}$ & $\begin{array}{l}2.58 \\
2.91 \\
2.74\end{array}$ & $\begin{array}{l}\text { High } \\
1.87 \\
1.87 \\
1.87\end{array}$ & $\begin{array}{r}\text { Meaningfulness } \\
\text { HEW } \\
\text { DAV }\end{array}$ & $\begin{array}{l}2.76 \\
3.07 \\
2.92\end{array}$ & $\begin{array}{l}1.98 \\
1.80 \\
1.89\end{array}$ \\
\hline $\begin{array}{l}\text { Short Latency } \\
\text { Nean }\end{array}$ & $\begin{array}{l}\text { ROMI } \\
\text { SER }\end{array}$ & $\begin{array}{l}2.83 \\
3.10 \\
2.96\end{array}$ & $\begin{array}{l}1.10 \\
1.14 \\
1.12\end{array}$ & $\begin{array}{l}\text { MOV } \\
\text { POK }\end{array}$ & $\begin{array}{l}2.96 \\
2.88 \\
2.92\end{array}$ & $\begin{array}{l}1.11 \\
1.18 \\
1.14\end{array}$ \\
\hline
\end{tabular}


Table 2

Mean Number of Trials to First Correct Forward Anticipation of Short- and Long-Latency Recognition Terms and Low- and High-Meaningfulness Terms by Study Time and Recall Time

\begin{tabular}{|c|c|c|c|c|c|c|c|c|c|}
\hline \multirow{4}{*}{$\begin{array}{l}\text { Meaning- } \\
\text { fulness }\end{array}$} & \multirow{4}{*}{$\begin{array}{c}\text { Recog- } \\
\text { nition } \\
\text { Latency }\end{array}$} & \multicolumn{4}{|c|}{1 Sec Study Time } & \multicolumn{4}{|c|}{ 31/2 Sec Study Time } \\
\hline & & \multicolumn{4}{|c|}{ Recall Time } & \multicolumn{4}{|c|}{ Recall Time } \\
\hline & & \multicolumn{2}{|c|}{$1 \mathrm{Sec}$} & \multicolumn{2}{|c|}{$31 / 2 \mathrm{Sec}$} & \multicolumn{2}{|c|}{$1 \mathrm{Sec}$} & \multicolumn{2}{|c|}{$31 / 2$ Sec } \\
\hline & & Mean & SD & Mean & SD & Mean & SD & Mean & SD \\
\hline Low & $\begin{array}{l}\text { Short } \\
\text { Long }\end{array}$ & $\begin{array}{l}11.48 \\
11.04\end{array}$ & $\begin{array}{l}8.19 \\
6.21\end{array}$ & $\begin{array}{l}6.58 \\
7.29\end{array}$ & $\begin{array}{l}4.22 \\
4.37\end{array}$ & $\begin{array}{l}6.54 \\
6.72\end{array}$ & $\begin{array}{l}2.93 \\
3.83\end{array}$ & $\begin{array}{l}4.29 \\
4.53\end{array}$ & $\begin{array}{l}1.93 \\
1.95\end{array}$ \\
\hline High & $\begin{array}{l}\text { Short } \\
\text { Long }\end{array}$ & $\begin{array}{l}7.29 \\
7.38\end{array}$ & $\begin{array}{l}3.82 \\
3.07\end{array}$ & $\begin{array}{l}7.81 \\
6.69\end{array}$ & $\begin{array}{l}5.33 \\
2.73\end{array}$ & $\begin{array}{l}5.00 \\
4.90\end{array}$ & $\begin{array}{l}3.23 \\
2.65\end{array}$ & $\begin{array}{l}3.90 \\
3.56\end{array}$ & $\begin{array}{l}1.28 \\
1.74\end{array}$ \\
\hline
\end{tabular}

randomiy to learn each of the two test lists. Within each of the above divisions, an equal number of both female and male $S s$ was assigned randomly to one of four st u d y-t i m e/recall-time presentation-rate combinations: a $1 / 1$-sec rate ( 1 sec for the stimulus term alone, $1 \mathrm{sec}$ for the stimulus and response terms together), a $3^{1 / 2} / 3^{1 / 2}$-sec rate $(31 / 2 \mathrm{sec}$ for the stimulus term alone, $3 \frac{1}{2}$ sec for the stimulus and response terms together), a $1 / 3^{1 / 2}$-sec rate ( $1 \mathrm{sec}$ for the stimulus term alone, $3^{1 / 2}$ sec for the stimulus and response terms together), and a $31 / 2 / 1-\mathrm{sec}$ rate $\left(3 \frac{1}{2}\right.$ sec for the stimulus term alone, 1 sec for the stimulus and response terms together). Within each presentation-rate group, an equal number of Ss was assigned randomly to each of the four tapes containing Lists 1 or 2 . All Ss were tested individually by one of three Es. Each $E$ tested an equal number of Ss within each of the treatment and control variables. All Ss were read standard PA instructions and given five trials on the practice list at a 3-sec presentation rate. Immediately following the practice trials, Ss were started on the test list. Since the eight PAs were presented in four different orders on each of the continuous loop tapes, each $S$ was presented a randomly determined first order. Any reasonable pronunciation of the response terms was allowed.

Learning trials were terminated at the end of one errorless trial. The learning score for a given PA for a given $S$ was the number of the trial on which $S$ made the first correct anticipation to that PA. Minimum performance criteria were the same as those employed by Ley \& Locascio (1970a).

\section{DESIGN}

The learning score for a given $\mathrm{S}$ on a CVC group was the mean of the learning scores of the two CVC units which comprised that group. The design employed a 2 by 2 by 2 by 2 mixed factorial in which study time and recall time were between-S factors and RL (short- and long-recognition latency) and $M$ (high and low) were within-S factors.

\section{RESULTS}

With respect to the primary purpose of the present study, both study time and recall time were significant factors, i.e., learning occurred in fewer trials under the $3 \frac{1}{2}-\mathrm{sec}$ study interval than under the 1 -sec study interval $[F(1,44)=12.92, p<.001]$ and in fewer trials under the $31 / 2-$ sec recall interval than under the 1 -sec recall interval $[F(1,44)=5.07, p<.05]$. However, recall time interacted with $\mathbf{M}$ $[F(1,44)=3.46, p<.05]$, i.e., the difference between the mean trials to learn the high- and low-M terms was greater under the 1 -sec recall interval than under the $3 \frac{1}{2} / 2$-sec recall interval. The $M$ by Study Time interaction was not significant $[F(1,44)=0.49$, p>.05], nor were any of the other interactions.

Consistent with previous research findings, the data provided in Table 2 show that the high-M response terms were learned in fewer trials than the low-M terms $[F(1,44)=11.12$, $\mathrm{p}<.001]$. However, within levels of $M$, the observed differences between short- and long-RL terms, as shown in Table 2 , were not significant $[F(1,44)$ $=0.31, \mathrm{p}>.05]$, nor were any of the interactions involving $\mathrm{RL}$.

With respect to acquisition, the mean number of trials required to learn a complete list under 1 -sec study and 1 -sec recall was 16.79 ; under 1 -sec study and $3^{1 / 2}$-sec recall, 13.12 ; under $31 / 2$-sec study and 1 -sec recall, 11.33 ; and under $3 \frac{1}{2}$-sec study and $3 \frac{1}{2}$-sec recall, 7.54

The results of the present study suggest that the previously observed interaction between presentation rate and $M$ is a function of recall time, i.e., the briefer the recall time, the greater the difference in learning rate between high- and low-M units. This finding might be accounted for on the basis of Martin's (1968) perceptual encoding hypothesis, which maintains that $M$ is inversely related to the number of perceptual/encoding responses a given nominal term elicits. Applying
Martin's encoding variability hypothesis to response terms, it follows that the encodings of low-M response terms would vary from study trial to study trial to a greater degree than would high-M terms, thus resulting in a greater number of encodings for low-M terms than for high-M terms. Assuming, however, that each encoding has a different probability for eliciting the nominal response term, the probability of a correct response (correct anticipation) is a function of which encoding is present at a given moment. In the case of very high-M units (units with but one perceptual encoding), recall within a given time interval is essentially an all or none phenomenon, i.e., either the encoded term is present or it isn't. If it is, the correct response occurs; if it isn't, the correct response does not occur. With low-M units, the situation is different, since at a given moment the presence of an encoding may or may not elicit the correct response, depending on the probability attached to the encoding. Assuming a perceptual trace mechanism against which the response elicited by the encoding is matched (e.g., Adams \& Bray, 1970), S could sample available encodings until the response term elicited matched the trace, and $S$ would then emit the correct response. Therefore, the duration of the recall interval should be sensitive to the effects of $M$, since low-M terms (terms with a relatively large number of encodings) are more likely to be recalled under a relatively long recall interval (e.g., $3^{1 / 2} \mathrm{sec}$ ) than under a relatively brief recall interval (e.g., 1 sec). On the other hand, high-M terms (terms with a relatively small number of encodings) have the advantage of greater recall probability under the relatively brief recall interval (e.g., $1 \mathrm{sec}$ ), but are not as greatly facilitated under the longer recall interval, since the sample of possible encodings is smaller and can, therefore, be matched against the perceptual trace in a relatively brief interval of time.

Differences in study time might not be expected to change the difference in performance between the high- and low-M pairs, even though the study period provides different amounts of time for rehearsal. If study involves encoding terms, making associations to the encoded terms and strengthening the associations through repetition, additional study time will facilitate performance only if the nominal term is encoded the same way from one study trial to another. Thus, if low-M terms are more likely to be encoded differently from study trial to study trial than high-M terms, any additional time for making associations and 
strengthening associations during the study interval will not be evidenced in improved performance until the nominal term is stably encoded. Therefore, differences between study times (within relatively brief intervals) should not change the differences in learning rates between high and low-M pairs.

With respect to the secondary purpose of the present study, the results indicate that within levels of equated $M, R L$ has no effect on PAL, whereas $M$ does. In view of the significant correlation $(\mathrm{r}=.36)$ between RL (associative latency) and PAL reported by Johnson (1964), but in the absence of any effect of $R L$. within levels of equated $M$, as found in the present experiment, the data of the present study suggest that $M$ is a correlate of $\mathrm{RL}$ and that differences in the observed RLs of verbal units within levels of equated $M$ are probably the result of measurement error.

\section{REFERENCES
ADAMS, J., \& BRAY, N.} theory of paired-associate verbal learning. Psychological Review, 1970, 77, 385-405.

JOHNSON, R. C. Latency and association value as predictors of rate of verbal learning. Journal ofVerbal Learning \& Verbal Behavior, 1964, 3, 77-78.

LEY, R. Associative reaction time, meaningfulness, and presentation rate in paired-associate learning. Joumal of Experimental Psychology, 1968, 78, 285-291.

LEY, R., \& ANDERSON, L. Associative reaction time of response terms in paired-associate learning. Iournal of Experimental Psychology, 1969, 79, 378-380.

LEY, R.. \& LOCASCIO, D. Associative reaction time and meaningfulness of C VCVC response terms in paired-associate learning. Journal of Experimental Psychology, 1970a, 83, 445-450.

LEY, R., \& LOCASCIO, D. Effects of associative reaction time and meaningfulness of stimulus terms in forward and backward paired-associate learning. Psychological Reports, 1970b, $27,867-873$.

MARTIN, E. Stimulus meaningfulness and paired-associate transfer: An encoding variability hypothesis. Psychological Review, 1968,75, 421-441.

NOBLE, $C$ E Measurement of association value (a). rated associations ( $\left.a^{\prime}\right)$, and scaled meaningfulness $\left(\mathrm{m}^{\prime}\right)$ for the $\mathbf{2 1 0 0}$ CVC combinations of the English alphabet. Psychological Reports, 1961, 8, 487-521. 